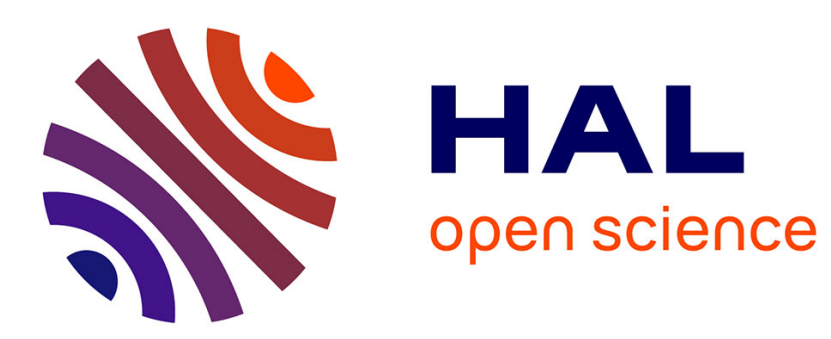

\title{
Performances and Design of Ironless Loudspeaker Motor Structures
}

Benoit Merit, Guy Lemarquand, Valérie Lemarquand

\section{To cite this version:}

Benoit Merit, Guy Lemarquand, Valérie Lemarquand. Performances and Design of Ironless Loudspeaker Motor Structures. Journal of Applied Acoustics, 2010, 71 (6), pp.546-555. 10.1016/j.apacoust.2009.12.004 . hal-00462380

\section{HAL Id: hal-00462380 \\ https://hal.science/hal-00462380}

Submitted on 9 Mar 2010

HAL is a multi-disciplinary open access archive for the deposit and dissemination of scientific research documents, whether they are published or not. The documents may come from teaching and research institutions in France or abroad, or from public or private research centers.
L'archive ouverte pluridisciplinaire HAL, est destinée au dépôt et à la diffusion de documents scientifiques de niveau recherche, publiés ou non, émanant des établissements d'enseignement et de recherche français ou étrangers, des laboratoires publics ou privés. 


\title{
Performances and Design of Ironless
}

\section{Loudspeaker Motor Structures}

\author{
B. Merit, G. Lemarquand and V. Lemarquand
}

\begin{abstract}
This paper presents several kinds of structures of ironless loudspeaker motors. The proposed devices go from simple structures, in terms of manufacturing process, to structures in which the magnet rings can be stacked, with different magnetization directions or values. The structures are studied and compared according to their created induction level and uniformity across the coil displacement range, which are directly linked to the loudspeaker performances (force factor). The model used is the coulombian model of magnets to calculate the magnetic field created, therefore all the calculations are analytical. The paper shows that no structure is universal when it comes to the loudspeaker design: some are well adapted to micro displacements of the coil while other structures are adapted to large displacements.
\end{abstract}

\section{Index Terms}

Permanent magnets, loudspeaker motor, loudspeaker performance, motor design, analytical magnetic field calculation, .

\section{INTRODUCTION} OUDSPEAKERS are widespread devices and many objects of our daily lives include one or more of them. They appeared a century ago and have of course evolved a lot, but the sound reproduction world is restlessly seeking improved loudspeakers with better integrated cabinets. What is expected from a 7 loudspeaker? It should simply be powerful, accurate and ever smaller, lighter, with an increased acoustical quality!

Manuscript Received December 12, 2007,2nd revision October 12, 2009. guy.lemarquand@ieee.org

The authors are with the Laboratoire d'Acoustique de l'Universite du Maine UMR CNRS 6613, Avenue Olivier Messiaen, 72085 Le Mans Cedex 9, France 
The power is linked to the acoustical flow, thus to the product of the axial displacement times the section of the emissive surface. If this surface is diminished and the power remains the same, then the displacement of the moving part has to be increased. In classical structures of electrodynamic loudspeakers, the increase of this displacement often means the increase of nonlinear effects and distortions.

Numerous studies of the loudspeakers highlight that their non-linearities have four major causes [1][2]: the defects of the motor, the acoustical propagation, the viscoelastic behavior of the suspension, and the vibrating modes of the emissive surface and of the moving part. Many solutions have been found in order to reduce these imperfections or their effects. Especially the drawbacks linked to the iron in the classical motor structures have already been described (reluctant force, Eddy currents) [3] and we presented a concept to get rid of them: structures of ironless loudspeaker motors [4]-[8].

The present paper goes further in this direction, describing different types of existing structures of ironless motors and comparing their performances. Predominantly we pay our attention on their ability to create a uniform induction over the axial trajectory of the coil. When this induction is uniform, the force that makes the coil oscillate, and consequently the coil support and the membrane, does not depend on the position of the coil anymore. Then all the non-linearities due to the motor are suppressed in such ironless loudspeakers.

In the same way, we evaluate structures on the space they need, especially in the axial direction of the loudspeaker. The more reduced the structure height is, the closer the coil can be to the cone diaphragm and the shorter the moving part can be: this is an advantage in terms of vibration modes.

\section{CONSIDERATIONS FOR THE STUDY}

The way the structures are presented in the following study, taking into account the various geometrical possibilities, is consistent with the way electrical machines are presented by Wang [9]. Many solutions have been imagined and studied to create homogeneous fields in closed cavities or open spaces and we meet here the same problematic [10]-[14]. Some of these structures were also applied to other purposes in electrical machines [15]-[17]. The reasoning used to associate magnets to create the intended magnetic field is the important and common point.

The structures presented are ring-shaped with rectangular sections. Then, the important point is to 
46

calculate the magnetic field created by such magnets or magnet assembly. The model chosen for the magnets is the coulombian one, which uses fictitious surface and volume charge densities to represent the magnet and thus to calculate the field they create in the space in and out of the magnet [18]-[25]. It has to be noted that the formulations obtained for the three components of the field are totally analytical. This enables easy optimization of the parameters of a structure, once a criterion is chosen.

Two kinds of applications are considered: the high frequency loudspeakers, for which the needed coil displacements are small, and the low frequency loudspeakers, which need large coil displacements. Typically, high frequency loudspeakers require peak-to-peak coil displacements smaller than $1 \mathrm{~mm}$ (tweeters) or reaching $3 \mathrm{~mm}$ (high medium loudspeakers); lower frequency loudspeakers can require peak-to-peak coil displacements of $10 \mathrm{~mm}$ (bass medium loudspeakers) and even larger than $20 \mathrm{~mm}$ (woofers).

The reference model usually describing the functioning of loudspeakers uses the Thiele\&Small parameters (lumped parameters) $R e, L e, B_{r} l, M m s, R m s$, and $K m s$. This useful model leads to a linear and stationary system of two differential equations:

$$
\left\{\begin{array}{l}
R e . i(t)+L e \frac{d i(t)}{d t}+B_{r} l \frac{d z(t)}{d t}=u(t) \\
M m s \frac{d^{2} z(t)}{d t^{2}}+R m s \frac{d z(t)}{d t}+K m s . z(t)=B_{r} l . i(t)
\end{array}\right.
$$

However it is known that loudspeakers are highly nonlinear devices [26]. And the dependence of the force factor $B_{r} l$ on the displacement $x(t)$ of the coil is among the major sources of non-linearities [27].

This $B_{r} l$ product, with $B_{r}$ the radial induction flowing through the coil of length $l$, determines not only the driving force $B_{r} l . i(t)$ for a given current $i(t)$, but also an electrical damping $B_{r} l . \frac{d z(t)}{d t}=B_{r} l . v(t)$ of the loudspeaker connected to an amplifier with low impedance output. Thus, variation of $B_{r} l$ versus displacement will produce two nonlinear terms in the differential equations. In both terms, time signals are multiplied. This multiplication produces new spectral components in the output signal measured and eared as harmonic and intermodulation distortions. Fig.9 of [28] shows how critical is the non-linearity due to the force factor $B_{r} l$, leading to a distorted signal with high amplitudes of the harmonic components. A symmetrical variation of $B_{r} l$ around the rest position of the coil leads to odd-order distortions; an asymmetry leads to even-order distortions and causes $40 \%$ of intermodulation distortions in a loudspeaker [29]. 


\begin{tabular}{|c|c||c|c||c|c||c|c|}
\hline$R e$ & $5.85 \Omega$ & $L e$ & $0.856 \mathrm{mH}$ & $B_{r} l$ & 9.04 T.m & $S d$ & $120.8 \mathrm{~cm}^{2}$ \\
\hline$M m s$ & $15.3 \mathrm{~g}$ & $R m s$ & $3.1 \mathrm{~kg} . \mathrm{s}^{-1}$ & $K m s$ & $5555.6 \mathrm{~kg} . \mathrm{s}^{-2}$ & $f s$ & $96 \mathrm{~Hz}$ \\
\hline
\end{tabular}

TABLE I

THIELE\& SMALL PARAMETERS OF THE MEASURED AND MODELED LOUDSPEAKER.

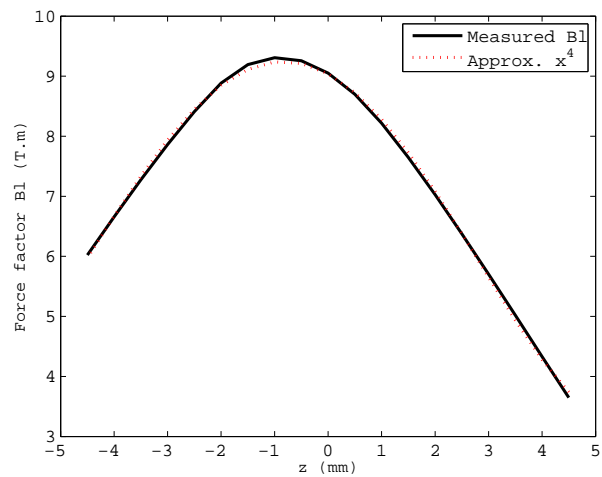

Fig. 1. Displacement-varying force factor $B l$ measured on the modeled loudspeaker (continuous line) and its model (dashed line).

\section{A. Definition of a linearity criterion related to the force factor}

1) Quantification of the distortions induced by a non-uniform force factor:

In this section, the simple linear model given by the system (1) is considered. In this system, a displacement-varying model of the force factor is introduced in order to visualize its effect on the calculated pressure response of a related loudspeaker. The considered lumped parameters are those of a classical loudspeaker whose force factor has been measured. Table I gives these parameters, used to solve the system (1).

The value of the force factor $B_{r} l$ given by Table I is only available at the rest position of the voice-coil of the loudspeaker. In reality, the force factor depends on the displacement of the voice-coil, and this variation is not symmetrical with the rest position, i.e. $z=0$, of the voice-coil (continuous line in Fig.1).

81 Its model of dependence is found using a $4^{\text {th }}$ order polynomial function. It well fits the values of the

82 force factor across the entire displacement range of the loudspeaker, as well as its derivative (dashed line

83 in Fig.1)

84 This model of dependence on the displacement is introduced in the system (1). The solving of this 85 system in the time domain allows the calculation of the displacement $z(t)$ of the voice-coil and of the 

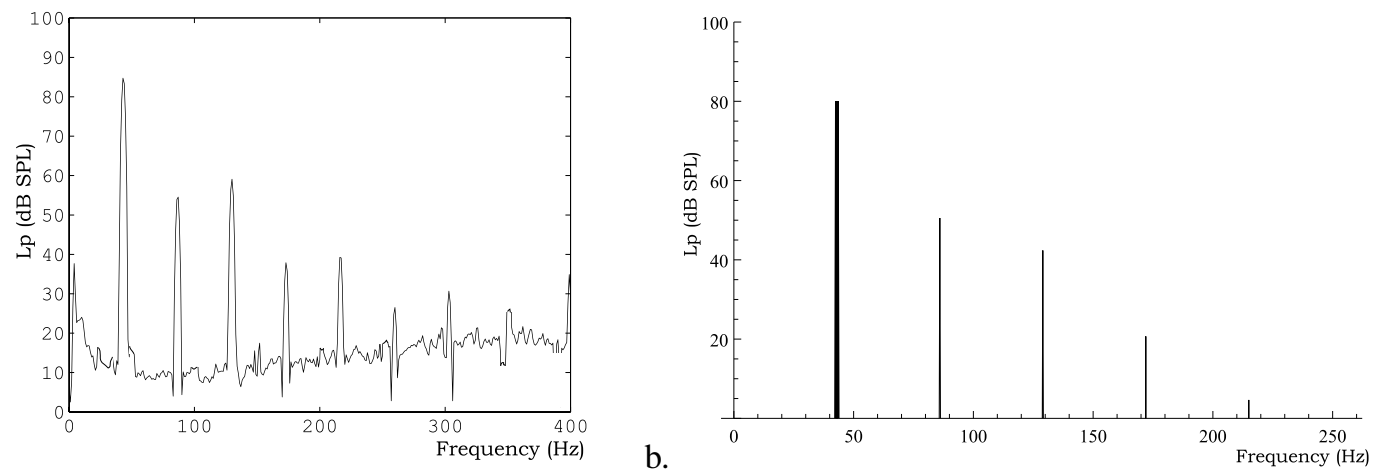

a.

Fig. 2. a. Measured sound-pressure spectrum of the loudspeaker supplied with a $5 \mathrm{~V}$ sinusoidal voltage at $43 \mathrm{~Hz}$ and b. calculated sound-pressure spectrum of the nonlinear model in response to the same excitation signal.

electric current $i(t)$ running through the voice-coil. These later variables are used to estimate the pressure response of the loudspeaker, in time and frequency domains.

The sound-pressure spectrum of the loudspeaker in response to a $5 \mathrm{~V}$ sinusoidal voltage at $43 \mathrm{~Hz}$ has been measured (Fig.2.a). This response is compared with the calculated spectrum thanks to the model (Fig.2.b). Despite this simple model only takes into account the nonlinearities created by the force factor, it well fits the real sound-pressure spectrum of the loudspeaker: the levels of the created harmonics are quite corresponding, even if even-order harmonics are higher in the model than in reality. Thus, this model can be used to understand the contribution of a non-uniform force factor on the distorted response of a loudspeaker.

Fig. 3 shows the time response of the voice-coil displacement to the previous excitation. The maximal reached displacement is only $1.2 \mathrm{~mm}$ while the voice-coil can move with a $\pm 4 \mathrm{~mm}$ displacement. To clearly see the effects of a non-uniform force factor, the excitation voltage is increased until the maximal displacement is $4 \mathrm{~mm}$. When the frequency is chosen equal to $43 \mathrm{~Hz}$, the $4 \mathrm{~mm}$ displacement is obtained with a $16 \mathrm{~V}$ excitation voltage. Fig. 4 shows the calculated time responses of the voice-coil displacement and of the current intensity to this increased excitation. The time signals are clearly distorted, and obviously lead to distortions in the frequency domain (see Fig.5). This figure 4 points out another problem related to a non-uniform force factor: the loudspeaker consumes more current but its voice-coil displaces less than in the linear case, which is the proof of a waste of energy. 


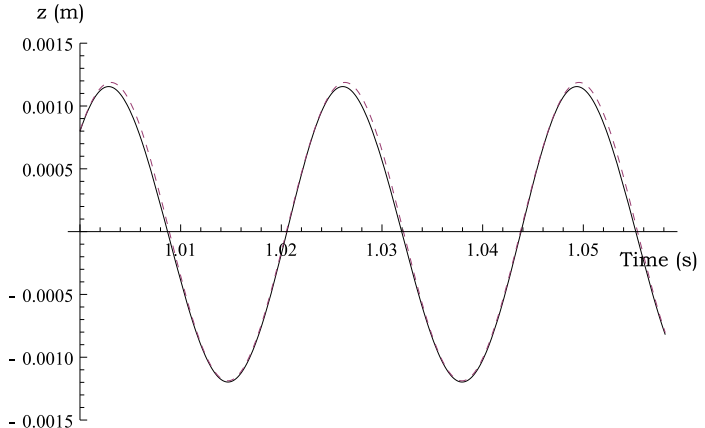

Fig. 3. Time variations of the voice-coil displacement in response to a $5 \mathrm{~V}$ sinusoidal voltage at $43 \mathrm{~Hz}$, calculated with the linear model (dashed line) and with the model including displacement-varying force factor (continuous line).
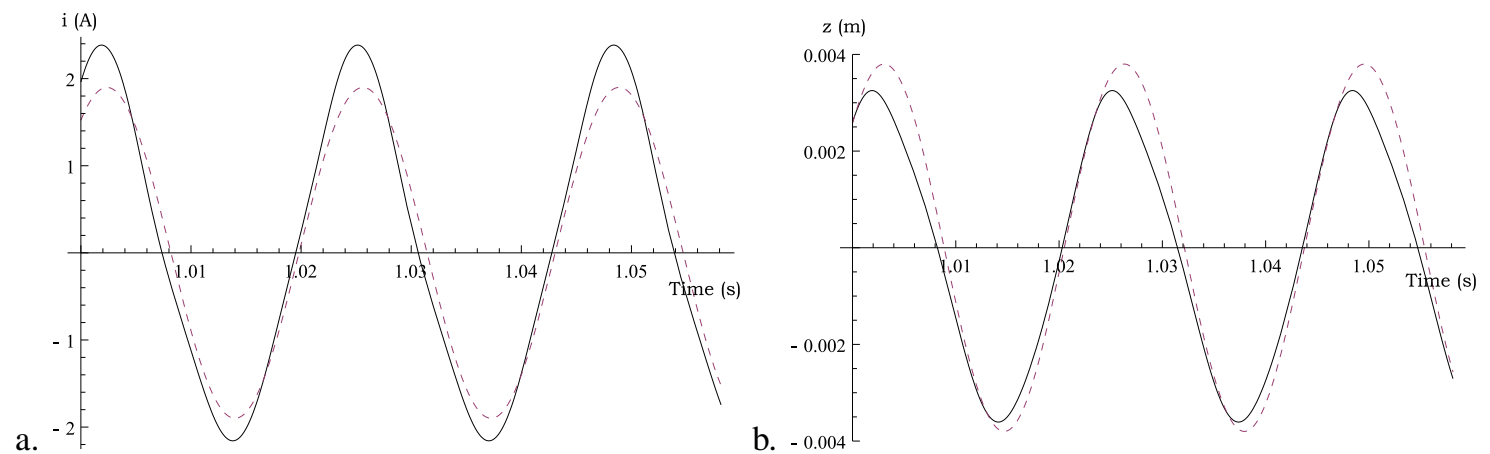

Fig. 4. Time variations a. of the current running through the voice-coil and b. of the voice-coil displacement, in response to a $16 \mathrm{~V}$ sinusoidal voltage at $43 \mathrm{~Hz}$, calculated with the linear model (dashed line) and with the model including displacement-varying force factor (continuous line).

Fig.5 is aimed to point out the harmonic and intermodulation distortions created by the loudspeaker whose force factor still varies like in Fig.1. Thus, the excitation signal is a two-tone excitation voltage: a $16 \mathrm{~V}$ one at $43 \mathrm{~Hz}$, to obtain the $4 \mathrm{~mm}$ displacement of the voice-coil, and a $20 \mathrm{~V}$ one at the arbitrary chosen frequency $500 \mathrm{~Hz}$.

When the voice-coil displaces across its entire displacement range, high harmonic distortion and intermodulation distortions are produced, because of the displacement-varying force factor. The higher harmonic component at $129 \mathrm{~Hz}$ is only $18 \mathrm{~dB}$ lower than the fundamental at $43 \mathrm{~Hz}$, and $13 \mathrm{~dB}$ lower than the fundamental at $500 \mathrm{~Hz}$. The higher intermodulation component at $414 \mathrm{~Hz}$ is only $19 \mathrm{~dB}$ lower than the fundamental at $500 \mathrm{~Hz}$ and $24 \mathrm{~dB}$ lower than the fundamental at $43 \mathrm{~Hz}$. With only two tones, the non-uniform force factor $B_{r} l$ induces a lot of distortions, most of them being potentially audible or 


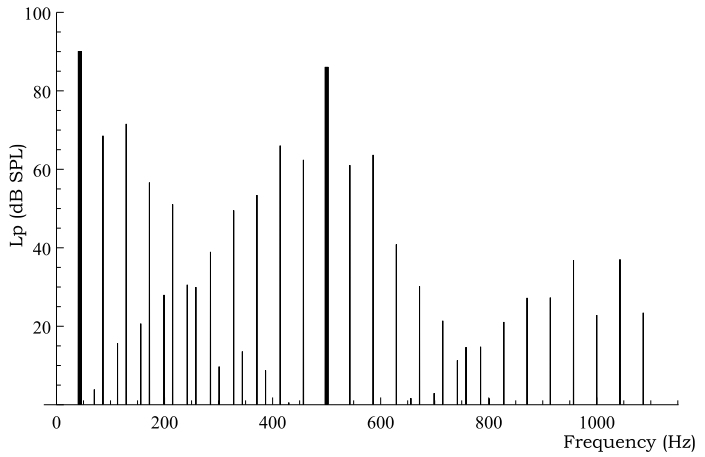

Fig. 5. Sound-pressure spectrum of the nonlinear loudspeaker model to a two-tone excitation voltage at $43 \mathrm{~Hz}(16 \mathrm{~V})$ and $500 \mathrm{~Hz}$ $(20 V)$.

disturbing for some applications [30],[31]. These effects are reinforced when talking about low frequency drivers, for which the displacements of the voice-coil are large, and for which the design of the motor becomes very difficult. But the distortions caused by a non-uniform force factor are also discussed in high frequency drivers [32].

These are the reasons why it is important to search for loudspeaker motors able to induce force factors $B_{r} l$ that do not depend on the displacement of the coil. The first step to the decrease of the nonlinearities due to the force factor can be to make its dependence on the displacement symmetrical with the rest position of the voice-coil. Thus, from the measured force factor, a model of force factor wih symmetrical dependence on the displacement we call symmetrical-made force factor is obtained (Fig.6). This symmetrical-made force factor has a $48 \%$ maximal peak-peak variation across a $\pm 4 \mathrm{~mm}$ range. As expected, Fig.7 shows that each even-order harmonic component is removed. In classical loudspeaker motors, making a symmetrical force factor is very difficult: it means creating a symmetrical magnetic induction in the airgap around the rest position of the voice-coil. The presence of iron makes this operation very difficult, and designers use tricks to evade this problem [33].

When the magnetic circuit is only made of magnets, the symmetry of the force factor is simply obtained thanks to the symmetry of the magnets disposition. In the sequel, we consider that the modeled loudspeaker creates a symmetrical magnetic induction in the airgap. To study the influence of the variation percentage of the force factor on the creation of distortions, we make its maximal variation vary from $48 \%$ (Fig.6 and Fig.7) to $1 \%$ across a $\pm 4 \mathrm{~mm}$ range. In Fig.8, the measured symmetrical-made force factor of the 


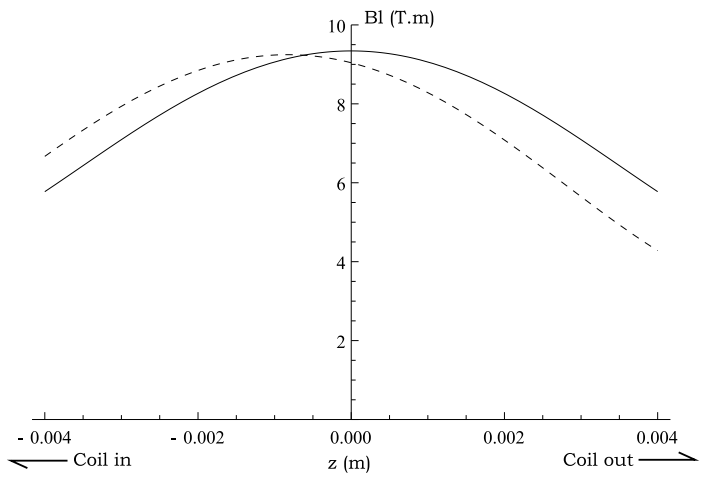

Fig. 6. Asymmetrical measured force factor of the loudspeaker (dashed line) and symmetrical-made force factor (continuous line) as a function of the voice-coil displacement.

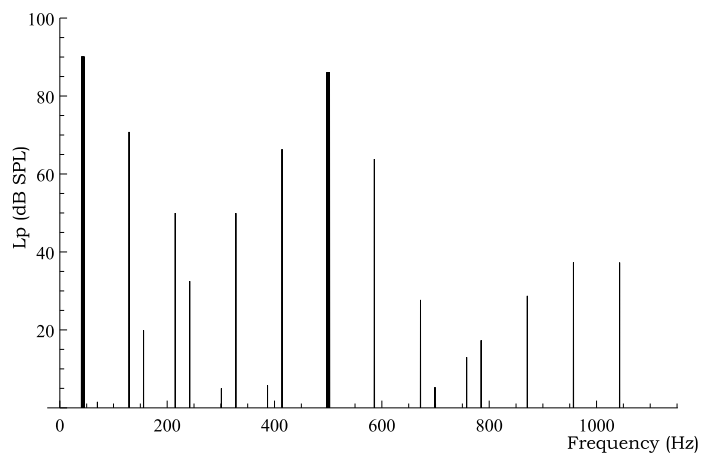

Fig. 7. Sound-pressure spectrum of the nonlinear loudspeaker model with the symmetrical-made force factor to a two-tone excitation voltage at $43 \mathrm{~Hz}(16 \mathrm{~V})$ and $500 \mathrm{~Hz}(20 \mathrm{~V})$.

real loudspeaker (thick line) has a $48 \%$ peak-peak variation, and is made even more uniform until $1 \%$ peak-peak variation.

Fig.9 to Fig.13 show the sound-pressure spectra of the modeled loudspeaker whose force factor maximal variation goes respectively from $30 \%$ to $1 \%$, in response to a two-tone excitation voltage.

From $30 \%$ to $1 \%$, the improvement in the reduction of the harmonic and intermodulation components is as much logical than necessary. When the $B_{r} l$ maximum variation reaches $1 \%$, the higher harmonic and intermodulation components are $50 \mathrm{~dB}$ lower than the fundamental components. The intermodulation components are known to be more disturbing than the harmonic components, as much in the signal generated by the loudspeaker [34]-[36] than in the auditive electric signal created by the ear itself [37]. That is why it is important to decrease these components as much as possible. Thus, searching for an 


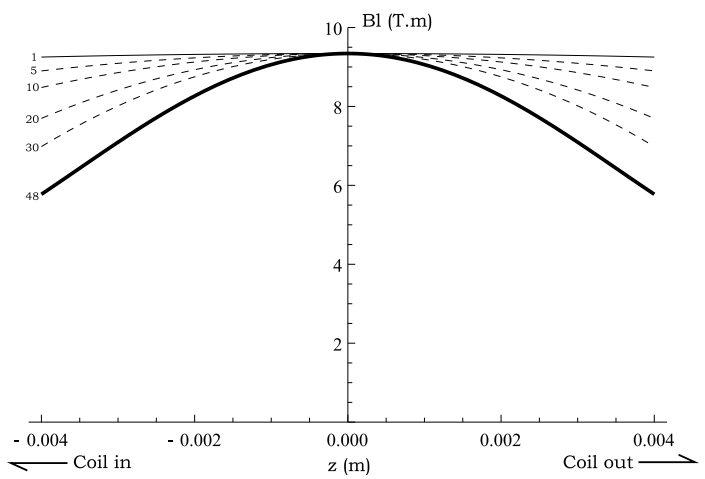

Fig. 8. Models of force factor as a function of the voice-coil displacement, and whose maximal peak-peak variation varies from $48 \%$ (thick line) to $1 \%$ (continuous line) across a $\pm 4 \mathrm{~mm}$ range. Dashed lines represent force factors with $30 \%$ to $5 \%$ maximal variation across the $\pm 4 \mathrm{~mm}$ range.

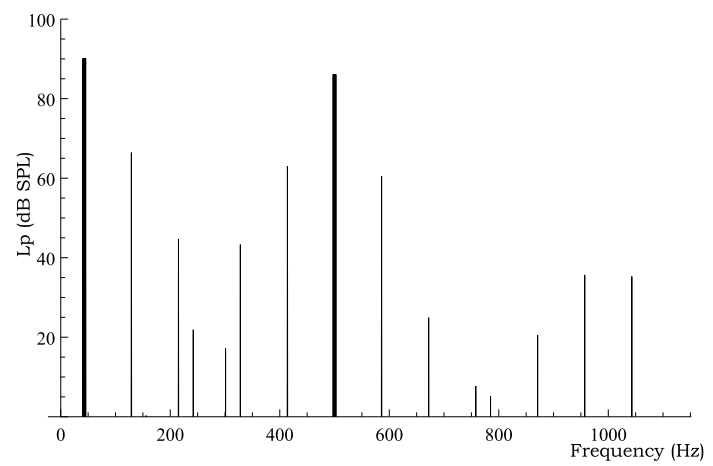

Fig. 9. Sound-pressure spectrum of the nonlinear loudspeaker model whose force factor has a maximal variation of $30 \%$ in response to a two-tone excitation voltage at $43 \mathrm{~Hz}(16 \mathrm{~V})$ and $500 \mathrm{~Hz}(20 \mathrm{~V})$.

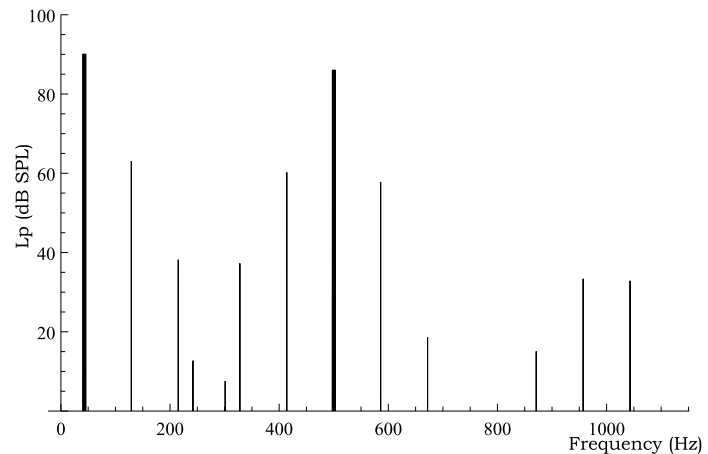

Fig. 10. Sound-pressure spectrum of the nonlinear loudspeaker model whose force factor has a maximal variation of $20 \%$ in response to a two-tone excitation voltage at $43 \mathrm{~Hz}(16 \mathrm{~V})$ and $500 \mathrm{~Hz}(20 \mathrm{~V})$. 


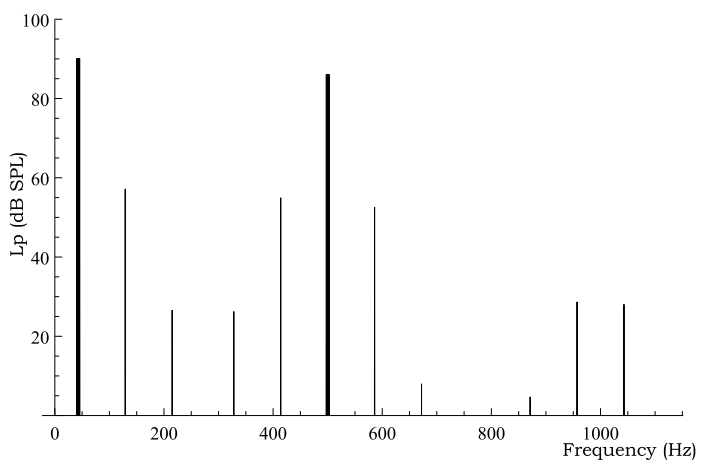

Fig. 11. Sound-pressure spectrum of the nonlinear loudspeaker model whose force factor has a maximal variation of $10 \%$ in response to a two-tone excitation voltage at $43 \mathrm{~Hz}(16 \mathrm{~V})$ and $500 \mathrm{~Hz}(20 \mathrm{~V})$.

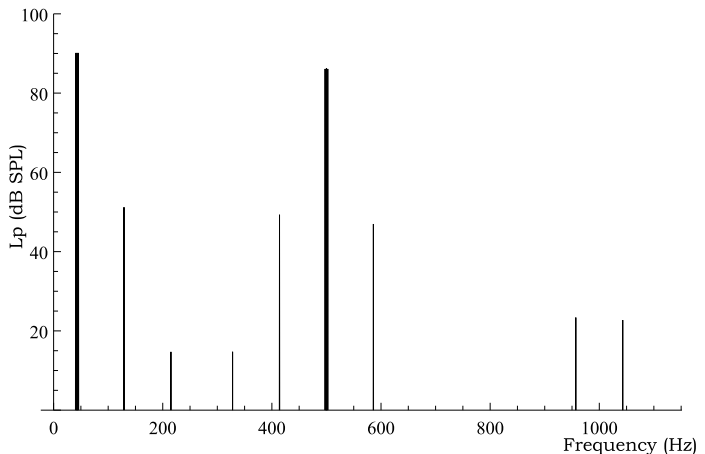

Fig. 12. Sound-pressure spectrum of the nonlinear loudspeaker model whose force factor has a maximal variation of $5 \%$ in response to a two-tone excitation voltage at $43 \mathrm{~Hz}(16 \mathrm{~V})$ and $500 \mathrm{~Hz}(20 \mathrm{~V})$

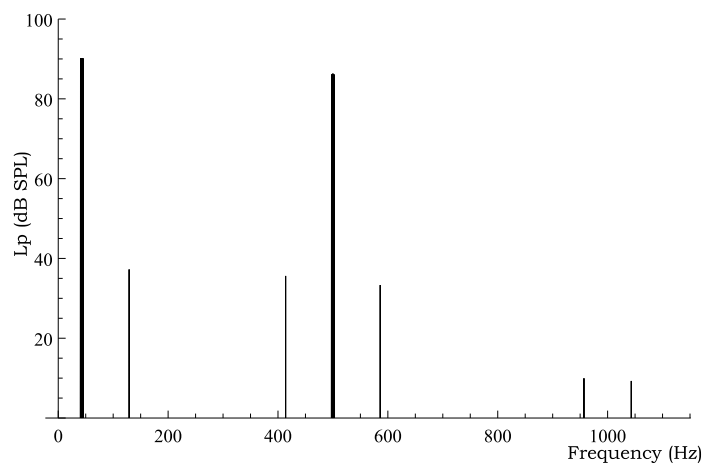

Fig. 13. Sound-pressure spectrum of the nonlinear loudspeaker model whose force factor has a maximal variation of $1 \%$ in response to a two-tone excitation voltage at $43 \mathrm{~Hz}(16 \mathrm{~V})$ and $500 \mathrm{~Hz}(20 \mathrm{~V})$. 
accurate loudspeaker motor is searching for a perfectly uniform force factor, whose maximal variation is $0 \%$ along the displacement range of the voice-coil. The constraints in the dimensioning of a traditional magnetic circuit imply that the designers would be largely satisfied with a variation of $1 \%$, given the low levels of the intermodulation components.

\section{2) Definition of the linearity criterion $z_{u n i}$ :}

The best way to the ideal 0\%-variation force factor is to search for a symmetrical ironless motor structure, which is able to create a magnetic field whose radial component is very uniform along the trajectory of the coil. Ideally, for an accurate and space-saving loudspeaker motor, a magnetic structure should create a perfectly uniform induction - i.e. with $0 \%$ variation - across a distance as large as the total heigth of the structure. This ideal structure is not realistic and we present in this paper existing structures that may approach the ideal case by optimizing their characteristics and by suffering a $1 \%$ peak-to-peak variation. It is not necessary to reach smaller variations than $1 \%$ : on the one hand the magnetization of the currently available magnets is not really uniform itself. And on the other hand, especially in the case of underhung loudspeakers, the force that makes the voice-coil oscillate is related to the mean value of the magnetic induction over the coil height (the coil height is the axial length of the coil). Therefore, if the induction variation across a range of displacement that interests us does not exceed $1 \%$, then the maximal force factor variation may not exceed $1 \%$. We have seen in the previous section that such a displacementvarying force factor is acceptable when looking at the level of the intermodulation components. That is why we consider that an induction with a $1 \%$ peak-to-peak maximal variation is sufficient to design an acceptable loudspeaker motor.

Thus, for the study, let us consider a parameter we call $z_{u n i}$. Given a structure, this parameter represents the axial distance across which the created magnetic induction seen by the coil has a peak-to-peak variation smaller than $1 \%$. Thus, across this distance, the induction and then the force factor are considered uniform. In classical loudspeakers, the $B_{r} l$ variation and the induction variation easily exceed $10 \%$ across a distance that corresponds to the trajectory of the coil; that is why significant nonlinear effects are produced and it is important to search for structures that lead to more uniform induction.

In the considered applications, the coil moves in a direction, $O z$, parallel to the revolution axis of 


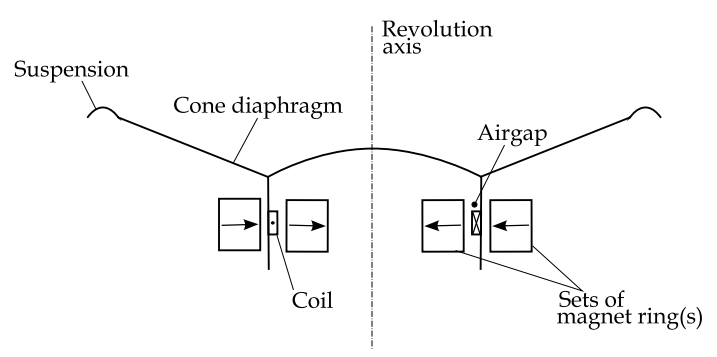

Fig. 14. General composition of an ironless loudspeaker; here the magnet structure is made with two sets of one magnet ring.

the loudspeaker (see Fig.14): the induction has to be uniform along this direction. $O z$ is the observation axis, placed in the airgap at a location that corresponds to the mean value of the coil thickness (the coil thickness is the radial length of the coil).

\section{SMALl DisPlacementS LOUDSPEAKERS}

The coil of a loudspeaker generally moves with small amplitudes at high frequencies. The following sections present the structures which are well adapted to these displacements. As the devices are often intended to be small themselves [38], we consider structures with only one outer set of magnet ring(s) and an inner coil (see Fig.15). The origin $O$ of the observation axis $O z$ corresponds to the center of the coil when this latter is in its equilibrium position. The induction is observed at a radial distance $a / 2=0.3 \mathrm{~mm}$ from the magnet ring(s). We compare structures that have approximately the same magnet volume with regard to their ability to create a uniform induction.

\section{A. Two axially magnetized permanent magnets: the simplest structure}

Structure $A$ of Fig.15 shows an ironless structure constituted by two axially magnetized rings. These rings are concentric, placed one above the other, and separated with an airgap of thickness $e$. Their respective magnetization are in repulsion -the facing poles are of the same kind-. The coil is centered in front of the airgap $e$ and the magnetic flux in the coil is then expected to be radial.

This kind of structure has been patented by the Harman society [39]. The main advantage of this structure is its simple manufacturing process, because it only requires classical axially magnetized permanent magnets. 

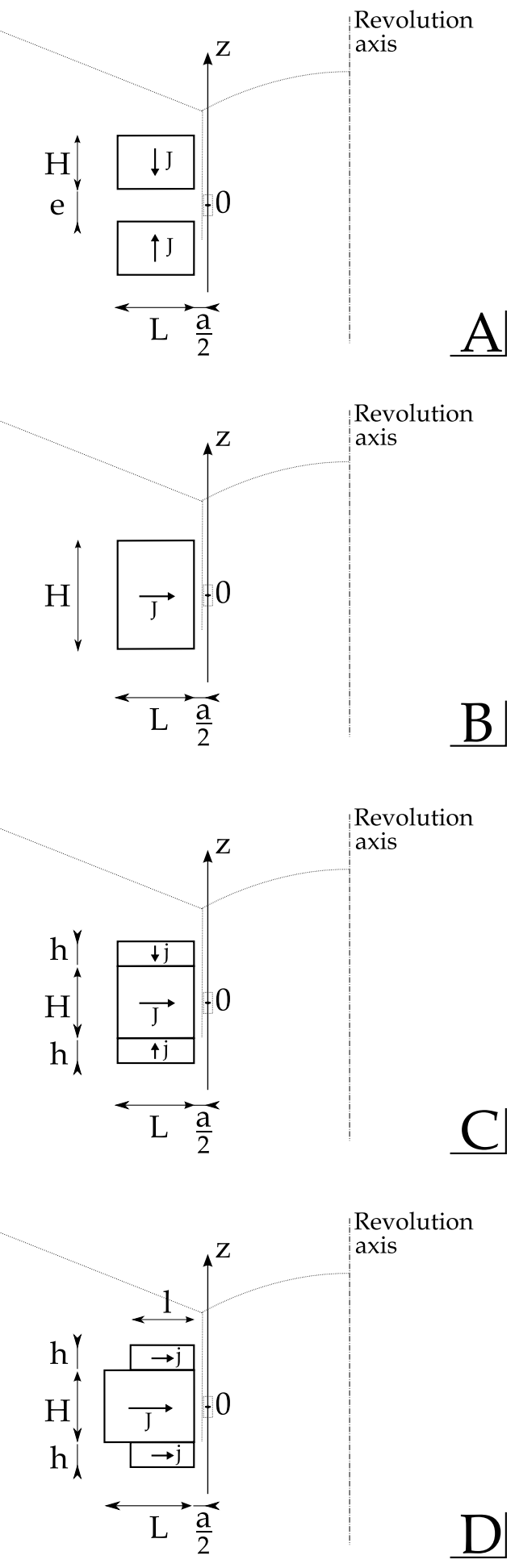

Fig. 15. Ironless motor structures for small displacements. The coil is located on the observation axis $O z$ and has an oscillating movement centered on the 0 point

A: two axially magnetized rings

$\mathrm{B}$ : one radially magnetized ring

$\mathrm{C}$ : one radially magnetized ring and two axially magnetized rings

D: three radially magnetized rings 


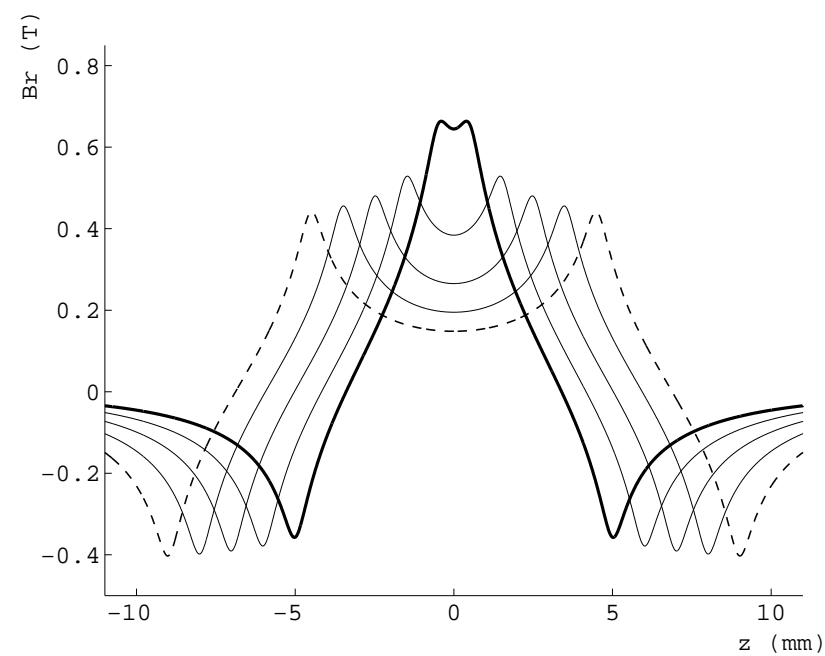

Fig. 16. Radial magnetic induction, $B_{r}(\mathrm{~T})$, along the observation axis at a distance $a / 2=0.3 \mathrm{~mm}$, created by the structure $A$ for $H=4.5 \mathrm{~mm}, L=9 \mathrm{~mm}$ and for various values of the distance between the magnets, from top to bottom , $e=1 \mathrm{~mm}$ (bold line), $3 \mathrm{~mm}, 5 \mathrm{~mm}, 7 \mathrm{~mm}$ and $9 \mathrm{~mm}$ (dashed line).

Fig.16 shows the global induction behavior when the magnets deviate. The induction intensity and the possible linear coil displacement $z_{u n i}$ decrease when $e$ decreases. For example, when the magnets are close to each other (see the solid bold line in Fig.16), the induction is intense (up to $0.6 T$ ) but the distance $z_{u n i}$ is so small that it is not convenient to represent it on the curve.

Thus, this structure is simple but, to prevent nonlinear phenomena, it should only be dedicated to tweeters for which the needed coil displacements are small.

\section{B. One permanent magnet ring radially magnetized.}

Let us consider the structure $B$ of Fig.15. It is constituted by one ring facing the moving coil. Ideally the ring is made in a radially magnetized permanent magnet. For a simpler design, it can also be made up of permanent magnet tiles - the same that are used in electrical machines- which are radially magnetized.

Previous studies [5] on the induction created by a rectangular magnet show that a good combination between its dimensions can always lead to a quite uniform induction in front of the magnets. In the best case, the axial distance $z_{u n i}$ is about $60 \%$ of the considered magnet height.

Fig.17 shows that, for a given length, the induction can be quite constant over an axial range if the magnet height is sufficient (dot-dashed line in Fig.17). This figure can also be interpreted alternately: it 


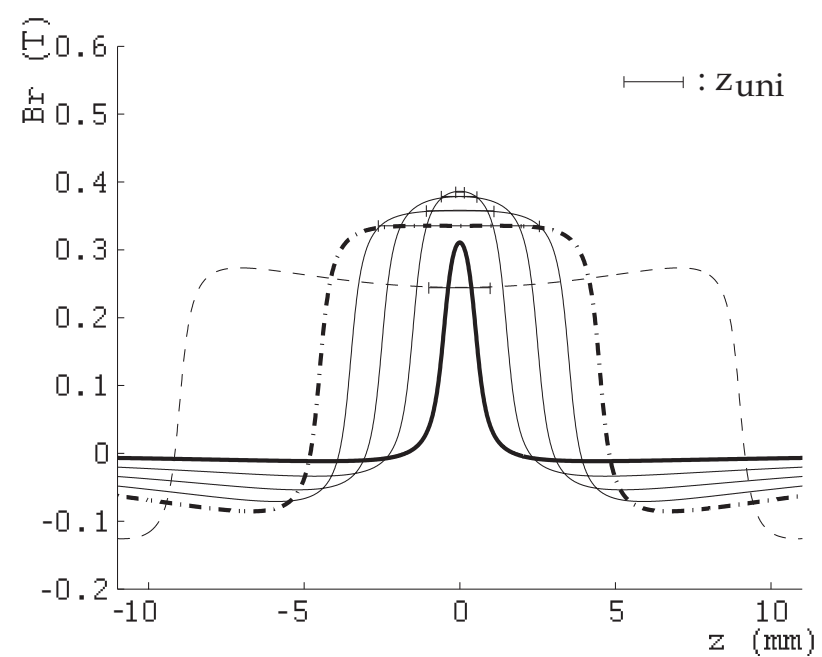

Fig. 17. Radial magnetic induction, $B_{r}(\mathrm{~T})$, along the observation axis at a distance $a / 2=0.3 \mathrm{~mm}$, created by the structure $B$ for $L=9 \mathrm{~mm}$ and for various values of the height: $H=1 \mathrm{~mm}$ (bold line), then from top to bottom $H=3 \mathrm{~mm}, 5 \mathrm{~mm}, 7 \mathrm{~mm}, 9 \mathrm{~mm}$ (dot-dashed line) and $H=18 \mathrm{~mm}$ (dashed line).

shows that small height magnets produce an important induction over short axial areas (see bold line in Fig.17). This localized action will be useful in further structures.

A structure $B$ of $9 \mathrm{~mm}$ long and $9 \mathrm{~mm}$ high is now compared to the structure $A$ proposed in the previous section: the magnet volume is the same in both structures. For the structure $B$, the induction is uniform over a range of $\pm 2.7 \mathrm{~mm}$ along the $O z$ axis around the middle of the magnet with a variation of $1 \%$ - so $z_{u n i}=5.4 \mathrm{~mm}$-. The induction intensity in front of the middle of the magnet is $0.33 T$ with a magnet magnetization of $1 T$ and with a magnet section of $81 \mathrm{~mm}^{2}$. The behavior difference compared to the structure $A$ is obvious: the induction level is smaller but is uniform over a significant range. If the length of the magnet decreases, the uniformity distance $z_{u n i}$ decreases. $z_{u n i}$ equals about $4 \mathrm{~mm}$ for a $7 \mathrm{~mm}$ length, and $1.6 \mathrm{~mm}$ for a $5 \mathrm{~mm}$ length. We conclude that the magnet length cannot go below a given value when the variation has to remain to one percent. If smaller, the magnet will not be well used. In fact, the set $L=H=9 \mathrm{~mm}$ is the optimum in this case. 


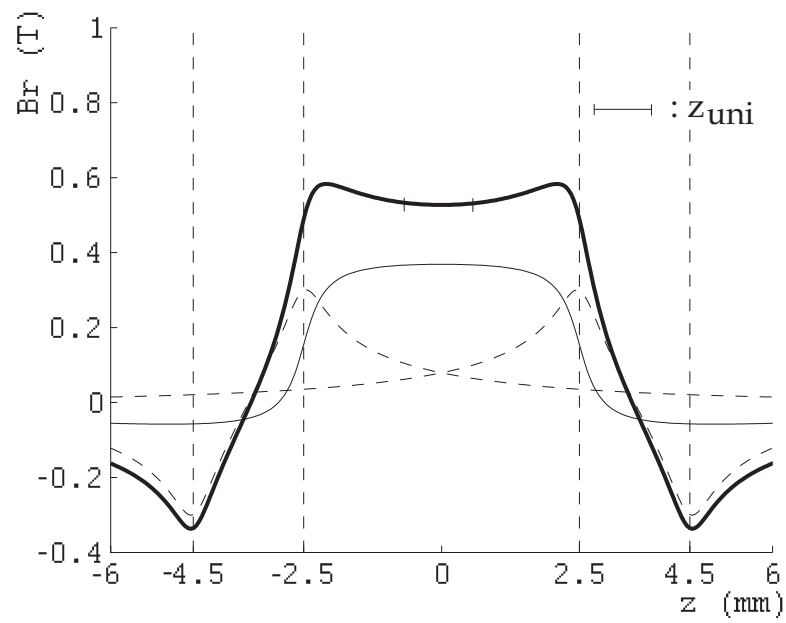

Fig. 18. Radial magnetic induction, $B_{r}(\mathrm{~T})$, along the observation axis at a distance $a / 2=0.3 \mathrm{~mm}$, created by the structure $C$ (bold line) with its central magnet with $H=5 \mathrm{~mm}, L=8 \mathrm{~mm}, J=1 T$ (full line) and its two external magnets with $h=2 \mathrm{~mm}$, $l=8 m m, j=1 T$ (dashed line).

\section{Combination of magnet rings}

The Sony society patented the structure $C$ of Fig.15 [40]. It is constituted by a stack of three magnet rings of equal length. It is notable that such stacked structures were proposed to enhance the performances of other applications such as passive magnetic bearings [41]. The central ring is radially magnetized while the external rings are axially magnetized and their magnetization directions help the total magnetic flux to close. According to the patent, the three magnetizations of the central ring, $J$, and of the external ones, $j$, are equal.

Let us consider the dimensions of the structure given in the patent: $H=5 \mathrm{~mm}, h=2 \mathrm{~mm}, L=8 \mathrm{~mm}$, with a magnetization of $1 T$. Fig.18 shows the induction calculated along the observation axis created by the whole structure (bold line) and by the separated elements. This induction is not really uniform. Its central value is $0.5 T$. The induction variation along the $O z$ axis over a range corresponding to the height of the central magnet represents $19 \%$ of the central value. Because of this significant variation, $z_{u n i}$ is only $1.28 \mathrm{~mm}$, that is $14 \%$ of the total height of the structure. Note that the induction variation is $10 \%$ across the distance of $4.2 \mathrm{~mm}$ that separates the two maxima of this induction.

The structure $C$, which is $11 \%$ more compact than the previous optimal structure $B$, produces a more 


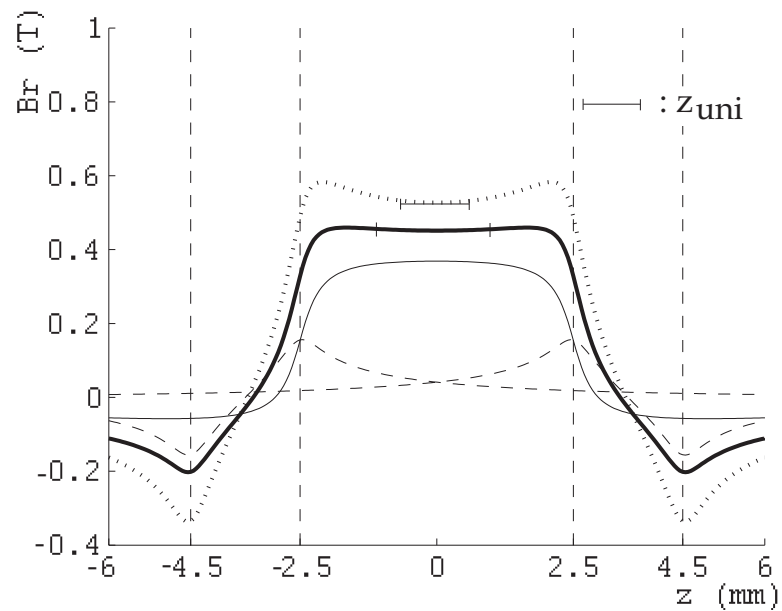

Fig. 19. Radial magnetic induction, $B_{r}(\mathrm{~T})$, along the observation axis at a distance $a / 2=0.3 m m$, created by the structure $C$ as patented (dotted line) and by the structure $C$ with lowered magnetizations (bold line); this structure uses a central magnet with $L=8 \mathrm{~mm}, H=5 \mathrm{~mm}$ and $J=1 T$ (full line) and two external magnets with $l=8 \mathrm{~mm}, h=2 \mathrm{~mm}$ and $j=0.52 T$ (dashed line).

intense induction but with a larger induction variation. The induction increases by $34 \%$ while the distance $z_{u n i}$ decreases by $76 \%$ compared to the optimal stucture $B$.

The principal advantage of the structure $C$ is then its ability to create really high induction levels while using relatively small magnet volumes. Despite its induction variation, the structure $C$ has on this point a substantial lead over the structure $A$. Nevertheless, because of its small $z_{u n i}$, and taking into account the behavior of its created induction, we conclude that the structure $C$ should be used for tweeters or high medium loudspeakers only.

In addition, Fig.19 shows that the total induction created by the structure $C$ can be more uniform if the magnetization of the external rings is smaller than the magnetization of the central ring. Fig.18 shows the contribution of each ring to the total induction and especially that the external rings (see dashed line in Fig.18) provide a really high magnetic induction compared to the induction provided by the central ring. Fig.19 shows the result when the external magnetizations are lowered to $0.52 T$. In this case $z_{u n i}$ equals $2.1 \mathrm{~mm}$, and the induction variation is $1.8 \%$ across the $3.4 \mathrm{~mm}$ distance that separates the two maxima of this induction. The uniformity improvement is significant but leads to a $8 \%$ decrease of the total induction. 


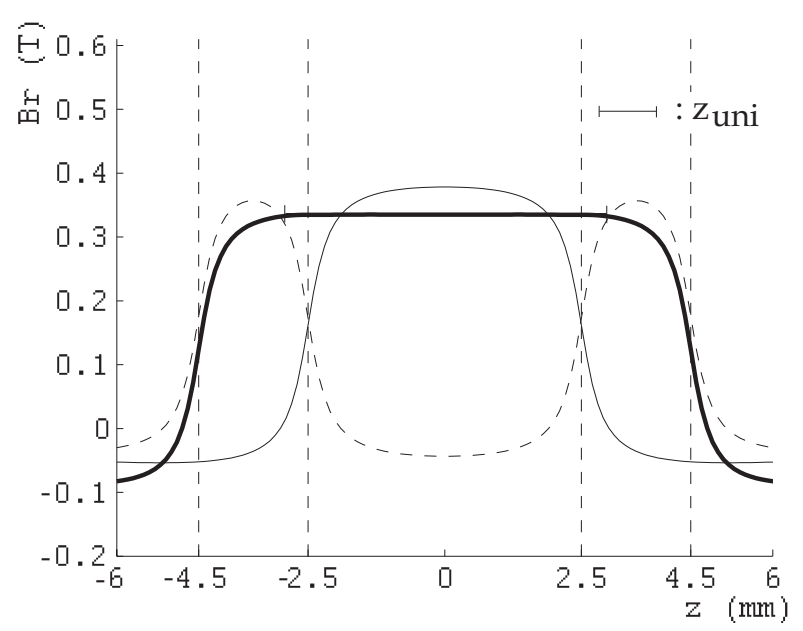

Fig. 20. Radial magnetic induction, $B_{r}(\mathrm{~T})$, along the observation axis at a distance $a / 2=0.3 m m$, created by the structure $D$ (bold line) with its central magnet with $H=5 \mathrm{~mm}, L=9 \mathrm{~mm}, J=1 T$ (full line) and its two external magnets with $h=2 \mathrm{~mm}$, $l=9 \mathrm{~mm}, j=1.01 T$ (dashed line).

\section{Several magnetizations}

The structure $D$ of Fig.15 goes further in the idea of using magnets whose magnetizations differ in order to give the intended flat shape to the observed induction. Like the structure $C$, it is constituted by one set of three stacked magnet rings, but their magnetizations are all radial. The purpose of the induction created by the external rings is to compensate the bell shape of the induction created by the central ring. This is achieved by combining the higher magnetization of the external rings and their small height to use their very localized action (as described in Fig.17).

Fig.20 shows the contribution of each ring and the resulting total induction (bold line). The set of dimensions is chosen in order to have the same magnet section as the one of the previous optimal structure $B\left(81 \mathrm{~mm}^{2}\right)$. The resulting induction has a $z_{u n i}$ of $6.4 \mathrm{~mm}$, which represents $67 \%$ of the total height of the structure. In fact, $z_{u n i}$ is larger than the height of the central magnet because the structure is calculated in order to create the most uniform possible induction across the height of the central magnet; across $H$, the induction variation is only $0.1 \%$.

In this case, the performance difference between both structures $B$ and $D$ is not significant, but it is important to note that the structure $D$ can be optimized. Indeed, the distance $z_{u n i}$ can always correspond 


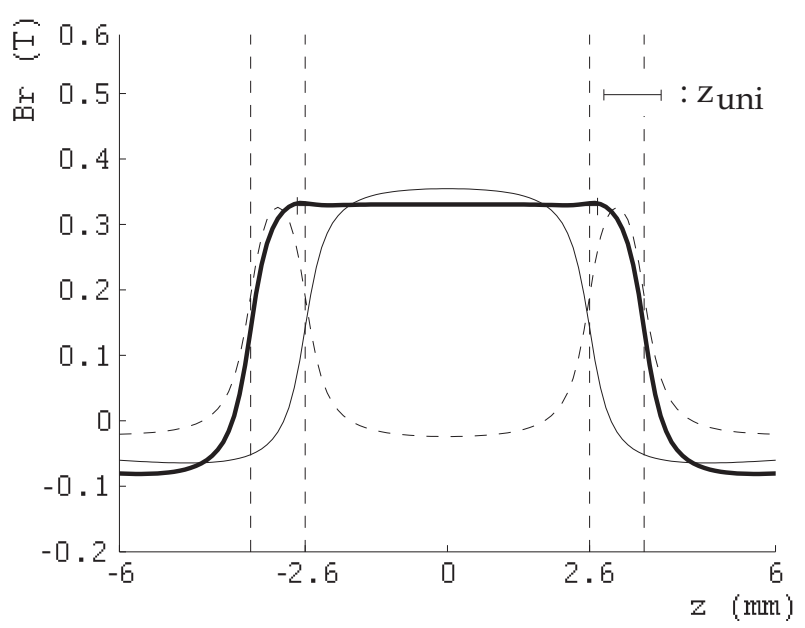

Fig. 21. Radial magnetic induction, $B_{r}(\mathrm{~T})$, along the observation axis at a distance $a / 2=0.3 \mathrm{~mm}$, created by the structure $D$ (bold line) with its central magnet with $H=5.2 \mathrm{~mm}, L=7 \mathrm{~mm}, J=1 T$ (full line) and its two external magnets with $h=1 \mathrm{~mm}$, $l=8.5 \mathrm{~mm}, j=1.09 T$ (dashed line).

to the dimension $H$, so the starting point of the optimization is facilitated by this occurence: the intended $z_{u n i}$ fixes the height of the central ring. The other dimensions and magnetizations are calculated in order to optimize the volume of the whole structure and the uniformity and the intensity of the magnetic field.

The previous geometry has been optimized in order to obtain an induction of equal intensity and having about the same $z_{u n i}$ of $5.4 \mathrm{~mm}$. The optimal dimensions we find correspond to a more spacesaving structure whose total height is $7.2 \mathrm{~mm}$. The total section of this structure $D$ is $53.4 \mathrm{~mm}^{2}(34 \%$ decrease compared to the previous section). The created induction reaches $0.33 T$ and the distance $z_{u n i}$ is $5.4 \mathrm{~mm}$ (see Fig.21).

The structure $D$ is now compared to the structure $C$ : the magnet volume is kept constant for both structures (Fig.22). The dimension $H=4 \mathrm{~mm}$ of the structure $D$ is arbitrary chosen so that $z_{\text {uni }}$ approximately corresponds to the distance between the two maxima of the induction created by the structure $C$.

While the total height of the structure $D$ is $7 \mathrm{~mm}$, that is $2 \mathrm{~mm}$ less than the structure $C, z_{u n i}$ equals $4.2 \mathrm{~mm}$. This represents a significant improvement compared to the distance $z_{u n i}$ of $1.28 \mathrm{~mm}$ obtained with the structure $C$. 


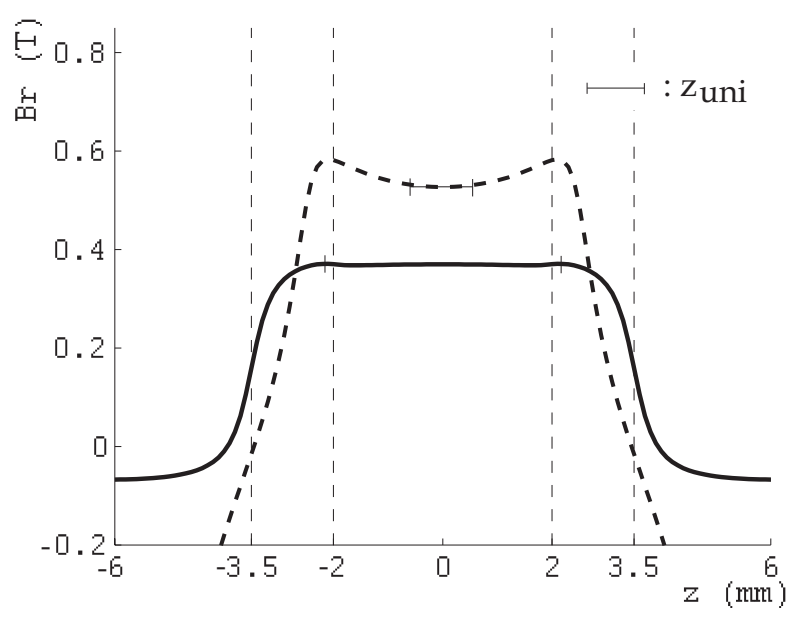

Fig. 22. Radial magnetic induction, $B_{r}(\mathrm{~T})$, along the observation axis at a distance $a / 2=0.3 m m$, created by the structure $D$ (bold line) with its central magnet with $H=4 \mathrm{~mm}, L=10.5 \mathrm{~mm}, J=1 T$ and its two external magnets with $h=1.5 \mathrm{~mm}$, $l=10 \mathrm{~mm}, j=1.05 T$, and by the structure $C$ as patented (dashed line).

The induction created by the structure $D$ reaches $0.37 T$, which represents a $37 \%$ decrease compared to the induction created by the structure $C$. Of course, the volume of the structure $D$ can be optimized. But, whatever the configuration is, it is not possible to reach an induction as intense as the one created by the structure $C$ without using big magnets. The reason is that the external rings of the structure $D$ are strictly compensation rings.

As a result, the structures $D$, with several magnetizations, lead to very compact devices that have a very uniform induction over a range that can be chosen. They allow the miniaturization of the device as well as a linear functioning, since a small coil easily remains in a uniform induction. The structure $D$ and the structure $B$ are well adapted to small displacements loudspeakers, but, thanks to their large $z_{u n i}$, they are not limited to these loudspeakers.

\section{LARGE DISPLACEMENTS LOUDSPEAKERS}

When fed with low frequencies, the coil of a loudspeaker moves with large amplitudes. So, the motor has to have good performances for large coil displacements. The requirements are more demanding than in the previous structures, since nonlinear effects increase with large displacements. The ironless structures which are well adapted to these requirements, that is displacements larger than $20 \mathrm{~mm}$, are presented in the 

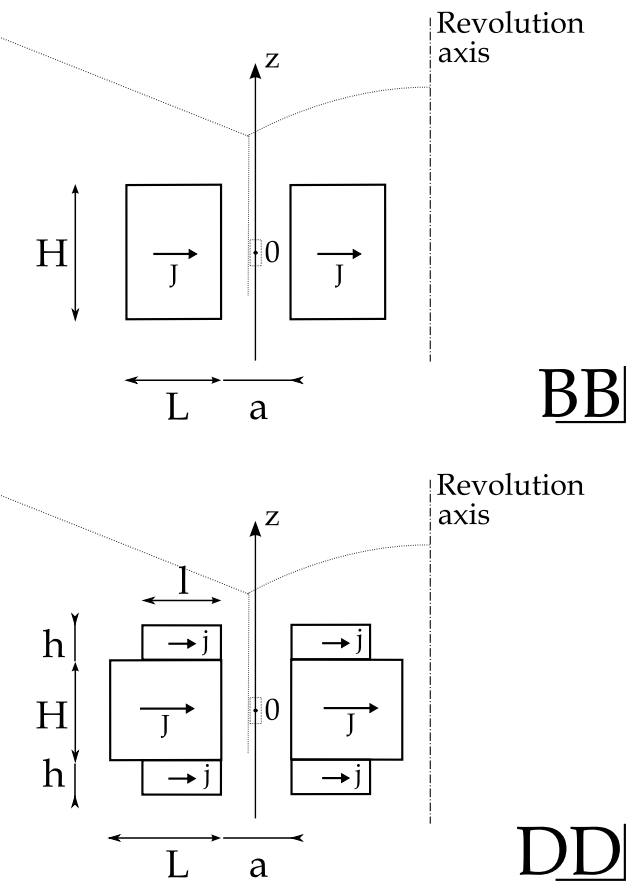

Fig. 23. Ironless motor structures for large displacements. The coil has an axial oscillating movement centered on the point 0 . BB: two radially magnetized rings

DD: two sets of three radially magnetized rings

following section. Given the conclusions of the first part concerning small displacements, and according to our calculations, the only structures that are well adapted to large and linear displacements are those inspired from the structures $B$ and $D$, as shown on Fig.23. Structures inspired from the structures $A$ et $C$ cannot be adapted for large displacements. Indeed the axially magnetized rings do not have effect anymore on the total induction when these two rings are too far from each other.

Hence, this section considers motor structures which are constituted by two sets of magnet ring(s) separated by an airgap where the moving coil is located. Having one or two sets of ring(s) does not change the behavior of the device, especially the uniformity of the field. However the induction intensity is increased. The calculation method is the same, as the superimposition theorem applies. The induction is calculated at a radial distance $a / 2=2 \mathrm{~mm}$ from the magnets. 


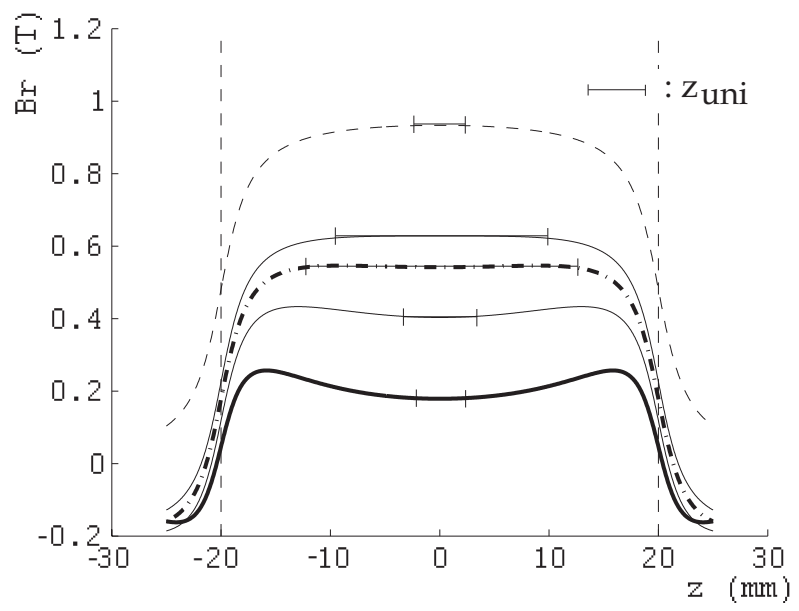

Fig. 24. Radial magnetic induction, $B_{r}(\mathrm{~T})$, along the observation axis at a distance $a=2 \mathrm{~mm}$, created by the structure $B B$ for $H=40 \mathrm{~mm}$ and for various values of the length, from bottom to top, $L=6 \mathrm{~mm}$ (bold line), $16 \mathrm{~mm}, 26 \mathrm{~mm}$ (dot-dashed line), and $36 \mathrm{~mm}$, and by the nearest face from the coil (dashed line).

\section{A. Two permanent magnet rings radially magnetized.}

Let us consider the structure $B B$ of Fig.23. This structure derives from the structure $B$. Of course the behavior of this structure is the same as the one of the structure $B$ presented for small displacements. Fig.24 illustrates the dimensioning of the device for large displacements.

For an arbitrary chosen magnet height of $40 \mathrm{~mm}$, and a length of $26 \mathrm{~mm}$, the induction is uniform over a range of $\pm 12.5 \mathrm{~mm}$ along the $O z$ axis around the point $O$ with a variation of $1 \%: z_{u n i}=25 \mathrm{~mm}$, which represents $63 \%$ of the height of the structure. The induction reaches $0.54 T$ in front of the middle of the rings for a magnet magnetization of $1 T$. The section of one magnet ring is $10.4 \mathrm{~cm}^{2}$. Note that the length $L=26 \mathrm{~mm}$ is the optimal length for this configuration: with other lengths, $z_{u n i}$ decreases.

\section{B. Several magnetizations.}

As it is natural to try to improve the performance of a device, the structure $D D$ of Fig. 23 is considered now. It is derived from the structure $D$ by concentrically placing two sets of three radially magnetized rings. Its behavior is the same as described in section III-D.

The previous structure $B B$ of $40 \mathrm{~mm}$ high and $26 \mathrm{~mm}$ long is compared with the structure $D D$. First, the magnet volume is kept constant for both structures (Fig.25). The chosen parameters for the structure 


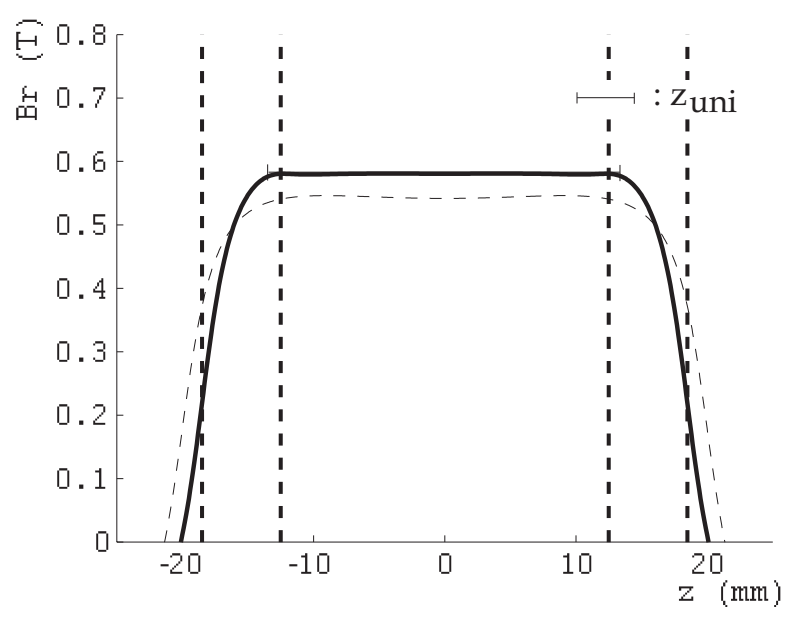

Fig. 25. Radial magnetic induction, $B_{r}(\mathrm{~T})$, along the observation axis at a distance $a=2 \mathrm{~mm}$, created by the structure $D D$ (bold line) with its central rings with $H=25 \mathrm{~mm}, L=30 \mathrm{~mm}, J=1 T$ and its four external rings with $h=6 \mathrm{~mm}, l=24 \mathrm{~mm}$, $j=1.07 T$, and by the structure $B B$ with $H=40 \mathrm{~mm}, L=26 \mathrm{~mm}, J=1 T$ (dashed line).

$D D$ are: $H=25 \mathrm{~mm}, L=30 \mathrm{~mm}$ and $J=1 T$ for the central rings, and $h=6 \mathrm{~mm}, l=24 \mathrm{~mm}$, and $j=1.07 T$ for the external rings. With a smaller height, then with a larger length, the structure $D D$ provides a more constant induction that reaches $0.58 T$. This is $7.5 \%$ higher than the induction intensity reached by the structure $B B . z_{u n i}$ is larger than $25 \mathrm{~mm}$ : it represents $71 \%$ of the total height of the structure. Thus, this structure $D D$ is more competitve but it is important to note that its external rings need a magnetization $j=1.07 T$.

The geometry of the structure $D D$ is now optimized in order to reduce its volume. The new parameters for the structure are: $H=25 \mathrm{~mm}, L=25 \mathrm{~mm}$ and $J=1 T$ for the central rings, and $h=5 \mathrm{~mm}$, $l=20 \mathrm{~mm}$, and $j=1.09 \mathrm{~T}$ for the external rings. Fig.26 compares this structure $D D$ to the same previous structure $B B$. The created induction reaches $0.55 T$ and $z_{u n i}$ is still larger than $25 \mathrm{~mm}$. The total magnet section of one set of the structure $D D$ equals $8.25 \mathrm{~cm}^{2}$. This represents a $21 \%$ decrease compared to the structure $B B$. While the total volume of the structure $D D$ is considerably reduced, its created induction is similar to the induction created by the structure $B B$, as much for its intensity as for its uniformity.

As for small displacements, the methodology for dimensioning the structure $D D$ is rather simple: the maximal displacement of the coil gives the height of the central rings, if the induction is intended to be 


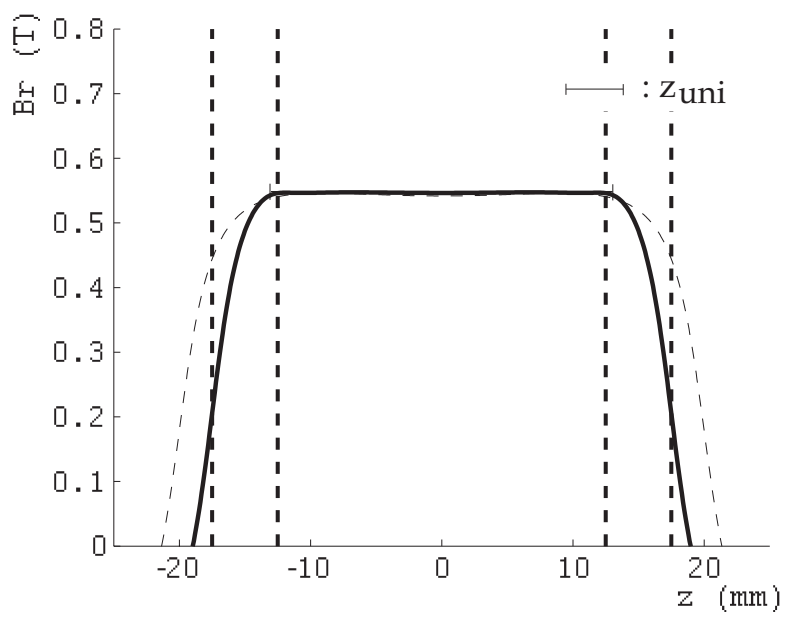

Fig. 26. Radial magnetic induction, $B_{r}(\mathrm{~T})$, along the observation axis at a distance $a=2 m m$, created by the structure $D D$ (bold line) with its central rings with $H=25 \mathrm{~mm}, L=25 \mathrm{~mm}, J=1 T$ and its four external rings with $h=5 \mathrm{~mm}, l=20 \mathrm{~mm}$, $j=1.09 T$, and by the structure $B B$ with $H=40 \mathrm{~mm}, L=26 \mathrm{~mm}, J=1 T$ (dashed line).

uniform over the whole displacement. Even in the case of large displacements, the optimization of the structure volume leads to compact devices that create very uniform inductions.

\section{CONCLUSION}

This paper presents several kinds of ironless structures of loudspeakers. The principal point of comparison between them is their ability to create a uniform induction. Based on this point, their study distinguishes the structures dedicated to small coil displacements and the ones that can also be dedicated to large coil displacements. While structures $A$ and $C$ should only be integrated in high frequency loudspeakers, it appears that structures $B$ and $D$ are more universal: their dimensions can be adjusted to correspond to small displacements (structures $B$ and $D$ ) as well as large displacements (structures $B B$ and $D D$ ).

Then, compromises are to be done between the difficulties in manufacturing the structure, its total magnet volume and of course the intensity and the uniformity of its created induction. The structure $A$ is the simplest structure to realize. But the technologies advancement makes radial magnetizations become more and more common, so that structures $B, C$ and $D$ are easy to realize. The volume of the magnet structure is an obstruction criterion as well as a price criterion; the structure $D$ well answers to both criterions. For efficient loudspeakers, the important point is the intensity of the induction. Both structures 
$A$ and $C$ create intense inductions in their reduced application domain. But the important point to obtain a good sound quality is to have a uniform induction over the whole excursion range of the coil. Whatever the range is, structures $B$ and $D$, and then $B B$ and $D D$, permit to obtain more accurate loudspeakers.

\section{REFERENCES}

[1] W. Cunningham, "Nonlinear distortion in dynamic loudspeakers due to magnetic effects," J.Acoust.Soc.Am., vol. 21, pp. 202207, 1949 .

[2] M. Gander, "Moving-coil loudspeaker topology as an indicator of linear excursion capability," J. Audio Eng. Soc., vol. 29, 1981.

[3] J. Vanderkooy, "A model of loudspeaker driver impedance incorporating eddy currents in the pole structure," J. Audio Eng. Soc., vol. 37, pp. 119-128, March 1989.

[4] M. Berkouk, V. Lemarquand, and G. Lemarquand, "Analytical calculation of ironless loudspeaker motors," IEEE Trans. Magn., vol. 37, pp. 1011-1014, March 2001.

[5] G. Lemarquand, "Ironless loudspeakers," IEEE Trans. Magn., vol. 43, pp. 3371-3374, August 2007.

[6] R. Ravaud, G. Lemarquand, V. Lemarquand, and C. Depollier, "Ironless loudspeakers with ferrofluid seals," Archives of Acoustics, vol. 33, pp. 3-10, 2008.

[7] B. Merit, G. Lemarquand, and V. Lemarquand, "In pursuit of increasingly linear loudspeaker motors," IEEE. Trans. Mag., vol. 45, no. 6, pp. 2867-2870, 2009.

[8] R. Ravaud and G. Lemarquand, "Modelling an ironless loudspeaker by using three-dimensional analytical approaches," Progress in Electromagnetics Research, PIER 91, pp. 53-68, 2009.

[9] J. Wang, G. Jewell, and D. Howe, "Design optimisation and comparison of permanent magnet machines topologies," vol. 148, pp. 456-464, IEEE Proc. Elect. Power Appl., Sept 2001.

[10] K. Halbach, "Design of permanent multiple magnets with oriented rec material," Nucl. Inst. Meth., vol. 169, pp. 1-10, 1980.

[11] M. Abele and H. Leupold, "A general method for flux confinement in permanent magnet structure," J. Appl. Phys., vol. 64, no. 10, pp. 5988-5990, 1988.

[12] M. Abele, J. Jensen, and H. Rusinek, "Generation of uniform high fields with magnetized wedges," IEEE Trans. Magn., vol. 33, no. 5, pp. 3874-3876, 1997.

[13] J. Jensen and M. Abele, "Generation of highly uniform magnetic fields with magnetized wedges," IEEE Trans. Magn., vol. 34, no. 4, pp. 2316-2323, 1998.

[14] R. Ravaud and G. Lemarquand, "Discussion about the magnetic field produced by cylindrical halbach structures," Progress in Electromagnetics Research B, vol. 13, pp. 275-308, 2009.

[15] L. Maosan, S. Caitu, C. Renhuai, W. Wentai, and Z. Jiemin, "Magnetic field analysis of rec devices with gradually varied magnetizations," in Proc. Of the 7 th Int. Workshop on RE Magnet and Their Applications, San Diego, CA, USA, pp. 165-173, 1983.

[16] M. Marinescu and N. Marinescu, "New concept of permanent magnet excitation for electrical machines. analytical and numerical computation," IEEE Transactions on Magnetics, vol. 28, pp. 1390-1393, march 1992. 
[17] Z. Zhu, G. Jewell, and D. Howe, "Design considerations for permanent magnet polarised electromagnetically actuated brakes," IEEE Transactions on Magnetics, vol. 31, pp. 3743-3745, november 1995.

[18] E. Furlani, S. Reznik, and A. Kroll, "A three-dimensonal field solution for radially polarized cylinders," IEEE Trans. Magn., vol. 31, pp. 844-851, Jan. 1995.

[19] J. Yonnet, "Magnetomechanical devices," in Rare-Earth iron Permanent Magnets (J. Coey, ed.), pp. 430-451, Clarendon Press, Oxford, 1996.

[20] E. Furlani, "Field analysis and optimization of ndfeb axial field permanent magnet motors," IEEE Trans. Magn., vol. 33, pp. 3883-3885, Sept 1997.

[21] Y. Zhilichev, "Calculation of magnetic field of tubular permanent magnet assemblies in cylindrical bipolar coordinates," IEEE Trans. Magn., vol. 43, pp. 3189-3195, July 2007.

[22] H. Rakotoarison, J. Yonnet, and B. Delinchant, "Using coulombian approach for modelling scalar potential and magnetic field of a permanent magnet with radial polarization," IEEE Trans. Magn., vol. 43, pp. 1261-12-4, April 2007.

[23] R. Ravaud, G. Lemarquand, V. Lemarquand, and C. Depollier, "The three exact components of the magnetic field created by a radially magnetized tile permanent magnet," Progress in Electromagnetics Research, PIER 88, pp. 307-319, 2008.

[24] R. Ravaud, G. Lemarquand, and C. Depollier, "Analytical calculation of the magnetic field created by Permanent-Magnet rings," IEEE Trans. Mag., vol. 44, no. 8, pp. 1982-1989, 2008.

[25] R. Ravaud, G. Lemarquand, V. Lemarquand, and C. Depollier, "Discussion about the analytical calculation of the magnetic field created by permanent magnets," Progress in Electromagnetics Research B, vol. 11, pp. 281-297, 2009.

[26] R. Ravaud, G. Lemarquand, and T. Roussel, "Time-varying non linear modeling of electrodynamic loudspeakers," Applied Acoustics, vol. 70, no. 3, pp. 450-458, 2009.

[27] W. Klippel, “Tutorial: Loudspeaker nonlinearities - causes, parameters, symptoms,” J. Audio Eng. Soc., vol. 54, pp. 907-939, Oct. 2006.

[28] W. Klippel, "Speaker auralization subjective evaluation of nonlinear distortion," presented at the AES 110th Convention, May 2001.

[29] W. Klippel, "Prediction of speaker performance at high amplitudes," presented at the AES 111th Convention, Nov.30-Dec.3rd 2001.

[30] L. Blondel and S. Elliott, "Electropneumatic transducers as secondary actuators for active noise control part i: Theoretical analysis," Journal of Sound and Vibration, vol. 219, pp. 405-427, 1999.

[31] S. Lane and R. Clark, "Improving loudspeaker performance for active noise control applications," J. Audio Eng. Soc., vol. 46, pp. 508-519, 1998.

[32] G. Hwang, H. Kim, S. Hwang, and B. Kang, "Analysis of harmonic distortion due to uneven magnetic field in a microspeaker used for mobile phones," IEEE Trans. Mag., vol. 38, pp. 2376-2378, 2002.

[33] V. Mazin and Y. Lee, "Non-uniform voice coil winding for electrodynamic loudspeaker," presented at the AES 116th Convention, May 2004

[34] E. Czerwinski, A. Voishvillo, S. Alexandrov, and A. Terekhov, "Multitone testing of sound system components - some results and conclusions, part 1: History and theory," J. Audio Eng. Soc., vol. 49, pp. 1011-1048, Nov. 2001. 
[35] A. Voishvillo, A. Terekhov, E. Czerwinski, and S. Alexandrov, "Graphing, interpretation, and comparison of results of loudspeaker nonlinear distortion measurements," J. Audio Eng. Soc., vol. 52, pp. 332-357, Apr. 2004.

[36] W. Klippel, “Assessment of voice-coil peak displacement x-max,” J. Audio Eng. Soc., vol. 51, pp. 307-323, May 2003.

[37] M. T. Abuelma'atti, "Prediction of the two-tone suppression and intermodulation performance of auditory systems," Applied Acoustics, vol. 67, pp. 882-891, Sept. 2006.

[38] H.C.Yu, T.Y.Lee, S.J.Wang, M.L.Lai, J.J.Ju, D.R.Huang, and S.K.Lin, "Design of a voice coil motor used in the focusing system of a digital video camera," IEEE Trans. Magn., vol. 41, pp. 3979-3981, Oct 2005.

[39] W. House, "Transducer motor assembly." US Patent 5,142,260, 1992.

[40] Ohashi, "Magnetic circuit and speaker." Patent EP 1553802 A2, 2005.

[41] J. Yonnet, G. Lemarquand, S. Hemmerlin, and E. Olivier-Rulliere, "Stacked structures of passive magnetic bearings," J. Appl. Phys., vol. 70, pp. 6633-6635, November 1991. 